fortune, like Hunter, to be classed with medical men-his writings to be confounded with medical writings; but their works were as strictly scientific as were those of Euclid and of Newton. Like all other men, he had his theories: one is remarkable, in so much that in the form of his own head was found its complete refutation. He fancied that, in accurate thinkers the brain, and, as a consequence, the skull, must be symmetrical. His own, as was proved after his death, was remarkably oblique, and the very reverse of symmetrical: obliquity of head implying obliquity of vision neither bodily nor mentally. In early life he ought to have abandoned the sterile field of medicine, and cultivated pure science.

The relative reputations of these two great men may be measured by the degree of universality to which their discoveries led. That of Cuvier spoke to mankind: it was Bichat's fate and misfortune to limit his researches to one animal-that animal, it is true, was man, great and all-powerful only in his own conceit. To the study of man alone Bichat devoted his genius and the labours of his life. The art of medicine he hoped to improve. Alas! his works, like those of Hunter, have ceased to be read by those for whom he wrote; but his name and the influence of his discoveries and views will remain for ever.

Conclusion. - The true descriptive method of anatomy was first discovered and applied to human structure by Bichat. Its relation to zoological science is direct-to medicine, as a science, indirect, exercising scarcely any influence over medicine as an art. Mechanical or operative surgery is based upon it. With physiology it has a few direct relations; but the greater number are indirect, vague, and of no account. Without it, the art of medicine would lose its best claim to be ranked as a profession; but it has not advanced it much, and probably never will. The springs of the action constituting life cannot be displayed by the scalpel and forceps: by its means we discover the effects of disease only, not diseases themselves. The nature of healthy or physiological action being entirely unknown, so also must be that of the pathological. Still more obscure are the effect of medicaments. In vain attempts to discover these relations were the lives of Bichat and of Hunter passed. Cuvier more fortunately applied the same element of research simply to science-to zoology-and so acquired immortal renown.

\section{DELIRIUM TREMENS TREATED WITHOUT OPIUM.}

By E. L. DIXON, Esq., M.R.C.S. EvG.

Is the treatment of delirium tremens, when the disorder is pure and uncomplicated, the use of opium has generally been considered to be of prime importance, indeed it has been thought an essential. But I observe that of late the administration of tartar emetic, in moderate doses, and without opium, has been ably advocated by Dr. Peddie. Now the object of this communication is to put forward a mode of treatment relying for success simply upon supporting diet of an unstimulating nature. I was led to adopt this method, which I have found succeed beyond my anticipations, in consequence of having had occasion to see one or two fatal cases, treated by full doses of opium, which presented all the symptoms of narcotic poisoning. Indeed, for some years past $I$ have been in the habit of treating all my cases, which have been numerous, in this way, and with an equally satisfactory result, the duration of them being tolerably equal. Of the last of them I subjoin a short account.

A tall, robust quarryman, aged thirty-eight, had been making use of intoxicating liquors of various kinds in great excess for seven weeks, when, (Oetober 10th, 1854,) from causes over which he had no control, he was at once deprived of them. On the morning of the 12 th he was first ouserved to be delirious, and when I saw him at nine A.M. I found him tremulous, very talkative, and labouring under ocular illusions, being particularly distressed about some little fishes crawling up his legs. His skin was warm and perspiring; the tongue coated with a moist whity-brown fur; appetite good; bowels confined. Pulse 100, soft and full. There was no headache, heat of scalp, or injection of the conjunctiva.

Two strong men were ordered to remain constantly with him, to prevent him injuring himself or others. His diet to consist of beef-tea, strong broths, with tea and bread and butter. To hare also a dose of common aperient mixture.

October 13 th. - He has been rery restless and talkative during the night, and this morning the tremnlousness is increased. Skin bathed in a profuse perspiration of a disagreeable odour; pulse 102, soft and full. Tongue coated with a fur of a brown colour, exhibiting a tendency to dryness; has taken all his allowance of food; the bowels have not been opened. Repeat the aperient.

14th. - The delirium during the past night has been of a more violent character, but now (nine A.M.) he is very tranquil, and appears exhausted, and oppressed with sleepiness. Tongue moist, and coated with a dirty-white fur; appetite continues good; pulse 100 ; the bowels have been opened once by the medicine.

15th. -Nine A.M. : He fell asleep yesterday at 11 A.M., slept three hours, awoke, slept again for an hour, and since one o'clock this morning has been asleep with trifling intermissions. Has no illusions, but is in a condition of bewilderment. Tremor; skin moist; pulse 85, soft and full.

16th. - Yesterday slept an hour during the day, and all last night. Is perfectly rational, but the tremulonsness is very great. He walks in a manner very similar to that of one under the influence of the exciting cause of his disorder. Pulse quiet; tongue somewhat coated; bowels open once yesterday.

17th. - Slept well last night, and is less tremulous this morning; tongue cleaning; appetite voracions; bowels confined; pulse quiet. Repeat the aperient; to have a chop.

19th. - Tremulousness subsided; is rapidly gaining strength; tongue almost clean; appetite good; bowels open.

In contrast with the above, I place an epitome of a case I attended some time ago, in conjunction with another medical man, and in which opinm was, I think, fairly tried.

On the evening of August the 10th, 1854, I saw a tradesman of this town, who was recovering from an epileptic paroxysin, the oceurrence of which, by-the-bye, I may remark I have frequently observed at the commencement of an attack of delirium tremens. I found that for some time previonsly he had been in the habit of drinking very freely, although he had never been intoxicated. During the whole of that day he had been in bed, and had vomited very frequently, the ejections containing bile; his bowels were open, but not purged. $\mathrm{He}$ was in a very tremulous condition, and mentally rather confused. An opiate draught was ordered to be taken directly, and an effervescing mixture every two hours.

He slept little during the night, and the next morning he was found to be labouring under a decided attack of delirium tremens. He was ordered to take fifteen minims of Battley's sedative solution every four hours, the diet to consist of strong broth; one or two persons to remain constantly with him, and the room to be darkened.

Althoush the opiate was continued withont intermission, and a draught, with a grain of morphia, administered for two or three nights, he continued in the same state of busy delirium for five whole days, when he fell asleep, and awoke comparas tively well.

Though, perhaps, it is scarcely fair to compare any two cases of a disease such as this, yet the circumstances of these, irrespective of their medical treatment, were as nearly similar as possible; and from their respective duration we see that the method of treatment without opium was the more advantageous, sleep being induced much more rapidly and certainly it is less homicidal. In other diseases, however, the nonemployment of a patent remedy may be equally cullable with its administration when not requirer.

To conclude, I consider that the chief indication in the treatment of delirium tremens is, to support the patient by plain and mutritious unstimulating food mil the brain has been restored to its normal state of nutrition, and the natural eliminative powers have removed from the system the poison producing the disorder. And such is the confidence I have in the treatment without opium, that I may say I consider those cases treated successfully with it get better in spite af it, and not by its assistance.

Preston, November, $185 \mathbf{1}$.

INCREASE OF BIRTHS.-154,735 births were registered throughout England in the quarter ending September 30th. This number, which exceeds by 7154 the number of births in the summer quarter of 1853 , is the largest number ever registered in the summer quarter, and allowing for increase of population, the rate of births, 3.294 per cent. per annum, exceeds the average $(3 \cdot 179)$. The chief increase of births has been in the counties of Essex, Suffolk. Norfolk, Wilts, Somerset, Stafford, Worcester, Lincoln, Durham, Northumberland, Monmouthshire, and South Wales. As 113,939 persons died in the summer quarter, the natural increase of population in the quarter was 46,796 . The increase of population is below the average. -Qu. ${ }^{3}$ terly Report of the Regietrar. General. 